\title{
Developing protocols for assessing the performance of Artificial Surfing Reefs - a new breed of coastal engineering
}

Emma J. Rendle, University of Plymouth, emma.rendle@plymouth.ac.uk Luciana Esteves, University of Plymouth, luciana.esteves@plymouth.ac.uk

\begin{abstract}
Artificial surfing reefs (ASRs) are a new breed of coastal engineering structures claimed to enhance local biodiversity, provide coastal protection and improve wave quality for surfing. By providing multiple functions, ASRs are often expected to contribute positively to the local economy, especially through tourism related to surfing and other water sports or beach uses. However, only few ASRs have been built worldwide and their performance is still debatable. At present, seven of these structures have been built worldwide, including one that has been uninstalled (California, USA) due to its poor performance and one that is unfinished due to increase in construction costs (Opunake, NZ). Unlike traditional coastal engineering structures (i.e. breakwaters and revetments), no regulations or protocols of good practice exist for the construction of ASRs. Due to the lack of independent studies and established monitoring protocols, relatively little is known about the impacts of ASRs on the coastal environment. Therefore, it is necessary to establish specific criteria to assess environmental and socio-economic impacts of ASRs, which can be used to objectively quantify their performance. Using the Boscombe reef as case study, this study suggests a set of criteria and methods that can form a protocol of good practice for the monitoring and performance assessment of ASRs. Implementation of protocols and regulations can provide information to support decision-making and inform stakeholders and end-users.
\end{abstract}

Key words: Artificial reefs, coastal protection, marine law, marine policy, amenity enhancement, surf tourism.

\section{Introduction}

An ASR is intended to provide tourist amenity by increasing the consistency of surfing waves and aid coastal protection. Designed specifically with surfing in mind an ASR aims to enhance surfing conditions and provide a tourism based infrastructure to the local economy. ASR Limited, a company based in New Zealand, is evolving the concept of artificial reefs for multi-purpose uses. The idea is based on replicating the effects of natural reefs in enhancing surfing and providing coastal protection observed world-wide [Mead and Black, 1999]. Additionally, it is expected that ASRs will improve local biodiversity. Seven ASRs have been constructed globally (two in New Zealand, two in Australia, one in the UK, one in India and one in the USA). There has been a growing interest on ASRs world-wide and the construction of new reefs have been discussed in countries such as Portugal, Brazil, Dubai and others. It is likely that the construction of the first ASR in Europe (Boscombe, UK, finished in October 2009) and in Asia (Kovalam, India, finished in February 2010) will bring more attention to these structures.

No regulations or protocols of good practice exist for the construction of ASRs. Due to the lack of independent studies and established monitoring protocols, relatively little is known about the impacts of ASRs on the coastal environment. With the increased interest in ASRs, it is now important that objective and independent monitoring studies are conducted to analyse their environmental impacts and measure their performance. Not only there is

This is an Open Access article distributed under the terms of the Creative Commons Attribution-Noncommercial License 3.0, which permits unrestricted use, distribution, and reproduction in any noncommercial medium, provided the original work is properly cited. 
insufficient published information available on shoreline response to ASRs, relatively little is known about shoreline response to submerged structures in general [Ranasinghe et al., 2006]. Research exists on the use of reefs for fisheries but due to differences in the design and material used, this knowledge might not be directly applied to ASRs.

Funding for the majority of ASR projects has been generated through the public sector, which expects to see financial investment returned to the local economy at least at the rates estimated by ASRs developers. For the Boscombe ASR, a feasibility study estimated a return of $£ 26$ for each $£ 1$ spent in the construction of the reef. Considering that $£ 3.03$ million has been spent so far in the Boscombe reef, it is expected that the ASR will generate about $£ 78.78$ million to the local economy. With high claims of cost to benefit ratio, ASRs are desirable to coastal managers interested in integrating coastal protection with tourist amenity. However, there is no clear definition on the ways this value was estimated and the time frame in which such return should be expected. It is necessary to establish specific criteria to objectively quantify the environmental and socio-economic impacts of the ASRs and measure their performance.

Using the Boscombe reef as case study, this study suggests a preliminary set of criteria and methods that can form a protocol of good practice for the monitoring and performance assessment of ASRs. Implementation of protocols and regulations can provide information to support decision-making and inform stakeholders and end-users. First, existing European and British regulations and laws related to similar structures are analysed. Second, the design and potential impacts of ASRs are discussed. Last, a protocol of good practice for the construction and monitoring of ASRs is proposed, addressing environmental, ecological and socio-economic aspects. Although specific methods need to be adopted to suit local specificity, it is expected that the protocol suggested here offers a generalised method for measuring performance that can be adapted for implementation worldwide.

\section{Current Law and Policy}

With reference to artificial reefs, [Whitmarsh, 1997] points out that arguably law and economics have received cursory treatment to date. This was addressed in The Convention for the Protection of the Marine Environment of the North-East Atlantic (the OSPAR convention) with the provision of guidelines on Artificial Reefs in relation to Living Marine Resources [OSPAR, 1999]. In more recent years, there has been some improvement after the European Artificial Reef Research Network project [Jensen et al., 2000] with the study of artificial reefs attempting to compile and combine research data. The OSPAR convention (1999) define an artificial reef as "a submerged structure placed on the substratum (seabed) deliberately, to mimic some characteristics of a natural reef" [Jensen et al., 2000].

Within Europe, the rapid growth of interest in ARs has outpaced the development of law applicable to such structures [Pickering, 2000]. Quite often a country's stance on AR deployment is based on opinion rather than reliable research. The legal requirements for permits and permissions vary widely across Europe; no two countries have the same approach to licensing reef deployment [Jensen et al., 2000]. In England and Wales, DEFRA (Department of Environment, Fisheries and Rural Affairs) have adopted an approach somewhere in-between. Any reefs deployed for other than experimental purposes will have to be multipurpose [Jensen et al., 2000], submerged structures for coastal protection are more likely to be consented than ARs for fisheries or tourism alone. The MMO (Marine Management Organisation) on behalf of DEFRA consult with the Environment Agency, CEFAS and the Crown Estate in order to produce a consent license to dump at sea under the Food and Environmental Protection Act 1985 (FEPA). This consent is in line with the 
Marine and Coastal Access Act (2009) and the EU's Integrated Maritime Strategy Blue Book (2009).

The Marine and Fisheries Agency (MFA) now the MMO (as of April 2010) as a Licensing Authority consented under Part II of the Food and Environment Protection Act 1985 to undertake the construction of an Artificial Surfing Reef at Boscombe, Bournemouth [MFA, 2009], the UK and Europe's first ASR. The FEPA license authorised for 'dumping of waste' (substances or articles) associated with these works namely; sand, plastic/synthetic and 'other'. Vague in description, the license leaves space for manoeuvre if there are changes to the original design. There are not specific laws and regulations that directly cover the use of artificial reef structures under the UK and EU laws.

\section{Existing knowledge on ASRs impacts and performance}

Environmental and socio-economic impacts of submerged structures are poorly understood. Little quantitative information exists by which to assess impacts of ASRs. Most of the monitoring studies related to the performance of ASRs are authored by professionals with a commercial interest in ASR development [Simioni and Esteves, 2010]. A summary of the existing knowledge on the impacts of ASR on the quality of waves for surfing, coastal protection, ecology and socio-economic aspects are presented below.

\subsection{Surf enhancement}

In his performance assessment of the Boscombe ASR, Davidson [2010] quantitatively assessed specified design criteria, comparing to conditions at the reef to the beach break. This independent reporting style gives a quantifiable and objective account comparable to future studies. He discusses the success in producing an additional surfing resource at Boscombe. However, the constructed reef performs loosely to the initial design; the wave is steep, frequently plunging and too challenging, and falls short of the original design plan. Observational evidence from Seafront Rangers suggests the reef is being surfed, although less consistently than the neighbouring beach. The reef failed to meet the design criteria to increased consistency in suitable waves for surfing. Other studies on wave quality at ASRs include; Narrowneck (Turner et al., 2004) and Cable's (Pattiaratchi, 2003) in Australia.

\subsection{Shoreline protection}

Although coastal protection is one of the claimed functions of ASRs, only the Narrowneck and Kovalam reefs have been build with the primary objective of coastal protection. Turner et al. [2004] suggest that some beach accretion was observed adjacent to the Narrowneck ASR. However, this might be due solely a consequence of the beach nourishment conducted in conjunction with the construction of the reef [Simioni and Esteves, 2010]. No other studies have investigated the effect of ASRs on the coastline. As observed with breakwaters, the Boscombe reef shows scour at the foot of the structure. More research is needed to assess the impact of scouring on the performance of ASRs. At Boscombe there is considerable exposure of the clay underlying the beach sand veneer due to scouring around the reef. It is unknown whether this is a localised and temporary effect, but the impact of exposing different substrate on the local biota needs to be investigated.

Conventional breakwaters and beach protection structures (e.g. groynes and breakwaters) are becoming increasingly unpopular, mostly due to their adverse impact on beach amenity and aesthetic value [Ranasinghe et al., 2006]. In a move to make shoreline stabilisation more attractive than the traditional rock and concrete hard structure, coastal management are enlisting alternative materials for construction. With an the increasing need for more economical and environmental designs and shortage of natural rock (for hard structures) and 
sand (for beach nourishment) in certain areas have stimulated in recent years the alternative designs utilising geosystems and local materials [Pilarczyk, 1998]. However, the material is not as resistant to mechanical damage, so care must be taken when designing and handling geotextile systems [Black et al., 2006] as well as post-construction protection.

\subsection{Ecology}

ARs are assumed to cause aggregation of scattered specimens and secondary biomass production through increased survival and growth of juveniles [Edelist and Spanier, 2009]. The construction of the ASR modifies natural habitat (e.g. substituting a soft unconsolidated bottom by a semi-solid, firm geotextile surface), which in principle can increase the local biodiversity and species abundance. Usually, this is seen as a positive argument although some argue negative impacts occur when altering a natural ecosystem, no matter how apparently barren. New colonisers put pressure on commodities, causing competition for food and space, encouraging the migration of foreign species and increasing predation of native species. Artificial reefs affect the substrate characteristics and the food resources available to an assemblage [Davis et al., 1982]. Similarly, changes in hydrodynamics provide sessile species shelter; however the predator has an easier environment in which to hunt prey. Colonisation of an ASR will more likely reflect 'hard' coastal protection structures. Although, different substrate surface texture, encrusting or 'fouling' species and mobile species will diverge from those species with the ability to colonise an ASR.

It is unlikely that an ASR designed for coastal protection and surfing will have the specific AR design components of reefs designed for ecological purposes. The concept of multipurpose ASR benefiting needs of commercial fishermen, anglers, divers and nature conservation is an attractive one from economic and social view and a considerable design challenge for artificial reef scientists and engineers [Jensen et al., 2000]. Monitoring surveys indicate that biodiversity at the Narrowneck reef is lower than adjacent natural reefs but there are (qualitative) accounts that the ASR is popular with local recreational fishermen and divers [Jackson et al., 2005].

\subsection{Socio-economic aspects}

In 2002 it was estimated that there were 10 million surfers globally [Buckley, 2002; Corne, 2009]. Events and surfing competitions are highly publicised, their popularity rising rapidly internationally. On the Gold Coast, Australia, it is estimated that a single high profile surfing event is worth AU\$2.2M (GB£5.5M) [Mead, 2009; Raybould and Mules, 1998]. Demand for economic development in coastal communities, led to the desire of replicating the success of internationally acclaimed surfing locations. Few studies on surfing impact invariably show the high value of natural assets [Mead, 2009] however, these studies are often carried out by companies with a vested interest in the enhancement of surfing amenity. The cost:benefit prediction indicated for the construction of Narrowneck ASR was 1:60 [Raybould and Mules, 1998] whilst a lower ratio of 1:20 was estimated for Bournemouth [Black et al., 2000], it still represents a healthy return. Despite favourable estimates there is clearly no guarantee that economic effects of ASRs will be positive, and there is a danger that ARs will be constructed in circumstances which do not justify them [Whitmarsh and Pickering, 2000]. There are no studies of the actual economic return from the construction of ASRs.

Unfortunately, there has been a history of escalating cost surrounding construction of ASRs. Boscombe ASR had an original costing of $£ 800,000$ but a final construction cost in the region of $£ 3 \mathrm{M}$. This does not support studies evaluating construction costs produced by ASR Ltd 'that a single reef could replace two groynes, and that the construction cost would be similar' [Mead, 2009]. It is difficult to convince local population that such an investment that 
favours only a small group of people (i.e. the surfers) directly can bring revenue that will benefit the wider community indirectly.

\section{Protocol of good practice for the construction and monitoring of ASRs}

Currently, there are no regulations that guide or control the construction of ASRs and little quantitative information exists by which to assess their impacts. Existing regulations for the construction of submerged structures can be adapted and applied to ASRs. Clear criteria should be used to assess the performance of ASRs in all the claimed functions. Importantly, baseline studies should characterise the environment before construction without which environmental impact assessment is difficult. Assessment of environmental conditions preconstruction should include: detailed topography/bathymetry of the beach, nearshore and reef area (with measurements of seasonal variability); sediment sampling of beach, nearshore and reef area (with knowledge of subsurface geology); characterisation of beach, nearshore and offshore biota (describing seasonality); characterisation of wave climate (with annual variations) and understanding of the existing economy. Post-construction monitoring is needed to measure impacts expected from the ASR. Therefore, a clear definition of the objectives and benefits is necessary prior construction to allow identification of adequate criteria to measure impacts and performance. Monitoring will dictate the necessity for potential structural alterations or complete removal in a worst case scenario (i.e. Pratte's Reef, California). Suggestions for the criteria used to assess performance and monitor impacts are provided in Table 1 with indications on the frequency and methods of surveys.

The installation of an artificial reef should be followed by a short, medium and long-term monitoring to verify whether management objectives are fulfilled and if anticipated net benefits materialise. It is suggested that a 1,3 and 7 year reporting stage plan is put forward initially, 5 years seems sufficient time for a relatively stable community to develop [Jensen et al., 2000] therefore monitoring should surpass this. Any significant modifications to the reef should include a first year report regardless of the stage of the monitoring program. To ensure impartial judgement, survey and analysis should be conducted by independent parties. Human interference and individual perception or opinion, will prove to confound results unless addressed in experimental design. It is suggested that any sampling designs are checked with a professional of a suitable independent organisation to ensure pseudoreplication is avoided and provide qualitative, robust information that is non-bias and reliable.

Table 1. Suggested protocol for environment impact and performance assessment of ASRs.

\begin{tabular}{|lll|}
\hline \multicolumn{1}{|c|}{ Aspect } & \multicolumn{1}{c|}{ Reason to report } & \multicolumn{1}{c|}{ Method and frequency of reporting } \\
\hline $\begin{array}{l}\text { Structural } \\
\text { Assessment }\end{array}$ & $\begin{array}{l}\text { Integrity of the geotextile Sand Filled } \\
\text { Containers (SFCs) and the ASR } \\
\text { structure (correspondence with planned } \\
\text { design, durability, physical stability and } \\
\text { structural integrity). }\end{array}$ & $\begin{array}{l}\text { Quarterly high resolution bathymetry surveying to assess } \\
\text { final ASR design and effects of subsidence and } \\
\text { accommodation in the first year and annually afterwards. } \\
\text { Quarterly SCUBA diver visual inspections to assess } \\
\text { integrity and durability of the geotextile SFCs. More } \\
\text { frequently if deemed necessary (e.g. following collision } \\
\text { incident with boat). }\end{array}$ \\
\hline $\begin{array}{lll}\text { Wave } \\
\text { characteristics }\end{array}$ & $\begin{array}{l}\text { Examine wave focussing and breaking on } \\
\text { the reef. Assess whether the enhanced } \\
\text { waves complies with the expected model } \\
\text { design. }\end{array}$ & $\begin{array}{l}\text { Measurement of the angle of wave incidence on the reef } \\
\text { relative to measured surfer tracks (see below). Modelling } \\
\text { can be used with the 'as built' bathymetry and real data } \\
\text { collected from wave buoys. Annually in the first three years } \\
\text { and again in year 7 if needed. }\end{array}$ \\
\hline 'Surfability' or & $\begin{array}{l}\text { Reef performance with respect to the } \\
\text { original performance based contract, an }\end{array}$ & $\begin{array}{l}\text { Ride angle, length, speed and direction can be estimated } \\
\text { using an experienced surfer with a Global Positioning }\end{array}$ \\
\hline
\end{tabular}




\begin{tabular}{|c|c|c|}
\hline $\begin{array}{l}\text { Surfing } \\
\text { Performance }\end{array}$ & $\begin{array}{l}\text { assessment of the surf quality. } \\
\text { Reef usage to ascertain whether the reef } \\
\text { is being surfed and the environmental } \\
\text { conditions under which surfing on the reef } \\
\text { are taking place. }\end{array}$ & $\begin{array}{l}\text { System (GPS) recording position during surfing sessions to } \\
\text { assess the 'surfability' of a break. Quarterly in the first three } \\
\text { years. } \\
\text { Beach rangers can collect data to generate tourism } \\
\text { statistics. Questionnaires and interviews can be used for } \\
\text { collecting surfers' perception. }\end{array}$ \\
\hline $\begin{array}{l}\text { Beach and } \\
\text { nearshore } \\
\text { morphology }\end{array}$ & $\begin{array}{l}\text { Measuring changes in coastal } \\
\text { topography/bathymetry allows assessing } \\
\text { the ASR performance in enhancing } \\
\text { coastal protection. Identifying impacts to } \\
\text { the coastal zone, intertidal area and swash } \\
\text { zone. } \\
\text { Pre and post-storm surveys can be } \\
\text { conducted sporadically if needed. }\end{array}$ & $\begin{array}{l}\text { Several methods can be used to measure beach } \\
\text { topography (e.g. total station, RTK-DGPS, Laser scanner). } \\
\text { The technique chosen must be accurate, repeatable and } \\
\text { comparable. Beach topography should be measured at the } \\
\text { lowest tide quarterly in the first three years and annually } \\
\text { afterwards. It might be necessary to measure an area that is } \\
\text { away from the direct influence of the reef to assess the } \\
\text { influence of natural changes in wave climate. Bathymetric } \\
\text { surveys should be conducted at least annually. }\end{array}$ \\
\hline $\begin{array}{l}\text { Sediment } \\
\text { characteristics }\end{array}$ & $\begin{array}{l}\text { Assess changes in sediment } \\
\text { characteristics at the beach, nearshore } \\
\text { and adjacent to the reef. } \\
\text { Assessment of the effects of accretion in } \\
\text { the lee of the reef and erosion/scouring } \\
\text { Link with the biological monitoring; coarser } \\
\text { grain sizes produce a harsher, more } \\
\text { abrasive environment, habitat change for } \\
\text { benthic species causes altered } \\
\text { biodiversity. }\end{array}$ & $\begin{array}{l}\text { Sediment sampling should be conducted at transects at the } \\
\text { beach and at selected locations in the nearshore (to be } \\
\text { defined based on local specificity) and at defined distances } \\
\text { from the reef. Sediment volume should allow grain size } \\
\text { analysis (variable depending on the method use to measure } \\
\text { grain size. It is preferable that samples are geo-referenced } \\
\text { for replication. Can be conducted with beach topography } \\
\text { and nearshore bathymetry. } \\
\text { Surface Scrapes or shallow coring using SCUBA or spring } \\
\text { loaded Box grabs, remotely operated from boat or kayak. }\end{array}$ \\
\hline $\begin{array}{l}\text { Oceanographic } \\
\text { and } \\
\text { Meteorological } \\
\text { conditions }\end{array}$ & $\begin{array}{l}\text { Data used for monitoring changes in } \\
\text { natural forcing conditions - essential for } \\
\text { interpreting changes in coastal } \\
\text { morphology bathymetry and for identifying } \\
\text { ideal conditions for surfing. }\end{array}$ & $\begin{array}{l}\text { Wave characteristics (height, period and direction), Wind } \\
\text { (speed and direction), Water level (tides and surges). } \\
\text { Continuous data collection using wave buoys deployed } \\
\text { locally, meteorological stations where feasible, and water } \\
\text { levels by installing a tide gauge or pressure sensors. }\end{array}$ \\
\hline $\begin{array}{l}\text { Biodiversity and } \\
\text { biomass }\end{array}$ & $\begin{array}{l}\text { Biomass/ abundance, species richness, } \\
\text { diversity and community structure } \\
\text { Quantitative monitoring of number of } \\
\text { species and individuals using standard } \\
\text { biological survey methods (at ASR and } \\
\text { Control site pre and post construction); } \\
\text { Quantify whether an ASR is increasing } \\
\text { stock numbers/biodiversity It is imperative } \\
\text { that the monitoring is initiated in feasibility } \\
\text { stages to record baseline information. } \\
\text { There can be no impact assessment } \\
\text { without understanding the environment in } \\
\text { which the planned reef is to be } \\
\text { constructed. } \\
\text { Indicators of biomass increase such as } \\
\text { growth rates of fish, fecundity of reef- } \\
\text { associated fish, and survivorship of } \\
\text { juveniles around artificial reefs. Labour } \\
\text { intensive study but needed if claims of } \\
\text { fisheries enhancement are important. } \\
\text { A study of Bird Diversity and population } \\
\text { might be interesting to determine the } \\
\text { influence of ASR in attracting birds. }\end{array}$ & $\begin{array}{l}\text { Several methods can be used and the most adequate } \\
\text { depends on local characteristics. } \\
\text { Annual Fixed Quadrate Surveys using divers } \\
\text { Annual Towed HD Video Transects - rapid, cost effective } \\
\text { information on species distribution and condition. } \\
\text { Dropdown cameras or ROV from boat - this is highly } \\
\text { dependent on the swell, current conditions. Driving ROV in } \\
\text { shallow waters is difficult and unreliable. Drop down camera } \\
\text { can prove successful in extremely calm conditions. } \\
\text { Baited Video Sampling (frame mounted camera to } \\
\text { observe mobile species) replicate sites, } 15 \text { min video } \\
\text { (number of individual species in } 1 \text { min segments). Fish size } \\
\text { can also be estimated. } \\
\text { Trammel Netting for description of population of sandy } \\
\text { bottom at ASR and control site } \\
\text { Present/Absent tests (measure of abundance) provide } \\
\text { spatial and temporal information on individual species. } \\
\text { An independent organisation (e.g. Seasearch, UK or local } \\
\text { University) provides valuable knowledge to a project, saving } \\
\text { time and resources in the identification and reporting of } \\
\text { marine biology. They coordinate divers with experience in } \\
\text { monitoring varied marine environments. }\end{array}$ \\
\hline $\begin{array}{l}\text { Chemical } \\
\text { analysis }\end{array}$ & $\begin{array}{l}\text { There is a lack of scientific knowledge } \\
\text { concerning the full environmental effects of }\end{array}$ & $\begin{array}{l}\text { Water Quality testing to assess leaching of substances } \\
\text { through the degradation of the geotextiles }\end{array}$ \\
\hline
\end{tabular}




\begin{tabular}{|c|c|c|}
\hline & & \\
\hline $\begin{array}{l}\text { Social-Economic } \\
\text { Impacts }\end{array}$ & $\begin{array}{l}\text { Quantitative description of the annual } \\
\text { revenue and net benefits generated by } \\
\text { the ASR } \\
\text { Assessment of the Novelty Factor of an } \\
\text { ASR, the variability in interest over time } \\
\text { Changes to local community and society } \\
\text { Impact to property market, availability of } \\
\text { jobs, income and benefits realised by the } \\
\text { tourism industry. } \\
\text { Quantify socio-economic impacts due to } \\
\text { enhanced fisheries and biodiversity } \\
\text { Economic appraisal of AR deployment is } \\
\text { essential to provide policy makers with key } \\
\text { information [Whitmarsh and Pickering, 2000] } \\
\text { to include in future coastal zone } \\
\text { management } \\
\text { Predicted verses actual cost:benefit ratio }\end{array}$ & $\begin{array}{l}\text { Recreation, leisure and tourism benefits and impacts - } \\
\text { increased visitor numbers positive for local economy, } \\
\text { however might generate beach crowding potentially } \\
\text { deterring visitors } \\
\text { Perception changes over time to the structure as well as } \\
\text { the concept } \\
\text { Long term and short term Questionnaires - local and } \\
\text { tourist visitors. Interviewing businesses, industry, tourists } \\
\text { and locals in the region - before and after construction. } \\
\text { Through close interaction with local fishers using } \\
\text { Participation methods/techniques economic impacts on } \\
\text { fisheries can be quantified } \\
\text { Contingent Valuation Method (CMV) and the Travel } \\
\text { Cost Method (TCM) include how travel costs incurred by } \\
\text { reef users reflect their 'willingness to pay' (WTP) for } \\
\text { recreational enjoyment, and hence the value of the reef } \\
\text { [Whitmarsh and Pickering, 2000] }\end{array}$ \\
\hline
\end{tabular}

\section{Conclusions}

Future ASR projects need to be investigated with the principles of coastal zone management in mind. Characterisation of the environment needs to be conducted pre-construction to serve as a baseline from which environmental impacts are quantified. The results of monitoring studies must be documented and reported in ways accessible to a wider audience (e.g. diverse stakeholders, end-users, general public and international scientific community). Implementing protocols of good practice can provide support in (a) regulating the implementation of ASRs; and (b) define standards for monitoring studies pre- and postreef construction. Three main benefits arise from establishing monitoring programs: (a) to assure compliance with conditions defined in the authorising permits, laws and regulations, (b) to provide assessment of predicted performance and ensure reef meets general standards and expectations and (c) to provide evidence that support future improvements of reef design and performance. The suggested monitoring protocol provides a reliable way of quantifying the impacts and measure performance of ASRs, which can be easily adapted to suit local specificity world-wide. This monitoring protocol is by no means exhausted. Project managers would be best advised to seek input from independent organisations with local knowledge in order to adopt the most adequate methodology and further investigate potential environmental impacts.

\section{References}

Black K., Blenkinsopp C., Mead S., Borrero J. C. and Frazerhurst J., 2006. Boscombe Construction Design and Environmental Effects. ASR Limited. Prepared for Leisure and Tourism, Bournemouth Borough Council.

Black K. P., Mead S. and Jackson A., 2000. Beach Amenity Options and Coastal Protection at Bournemouth, Artificial Surfing Reefs Ltd. Ragland, New Zealand,

Buckley R., 2002. Surf tourism and sustainable development in Indo-Pacific Islands. I. The industry and the islands. Journal of Sustainable Tourism, 10, 405-424.

Corne N. P., 2009. The Implications of Coastal Protection and Development on Surfing. Journal of Coastal Research, 25, 427-434. 
Davidson M., 2010. 6-Month Interim Report: Performance of Boscombe Surfing Reef, Bournemouth Borough Council, University of Plymouth, UK,

Davis N., Van Blaricom G. R. and Dayton P. K., 1982. Man-made structures on sediments: effects on adjacent benthic communities. Marine Biology, 70, 295-303.

Edelist D. and Spanier E., 2009. Influence of Levantine Artificial Reefs on the fish assemblage of the surrounding seabed. Mediterranean Marine Science, 10, 35-54.

Jackson L., Tomlinson R., Turner I., Corbett B., D'Agata M. and McGrath J., 2005. Narrowneck Artificial Reef Results of 4 years of Monitoring and Modifications. Proceedings of the 4th International Surfing Reef Symposium.

Jensen A., Collins K. and Lockwood A. P. M., 2000. Current Issues Relating to Artificial Reefs in European Seas. In: Jensen, A., Collins, K., and Lockwood, A.P.M (ed), Artificial Reefs in European Seas, Dortrecht, The Netherlands, Kluwer Academic Publishers.

Mead S., 2009. Multiple-Use Options for Coastal Structures: Unifying Amenity, Coastal Protection and Marine Ecology. Reef Journal, 1, 291-311.

Mead S. and Black K., 1999. A Multipurpose, Artificial Reef at Mount Maunganui Beach, New Zealand. Coastal Management: Taylor \& Francis Ltd, pp. 355-365.

MFA, 2009. License to Undertake Construction Works under FEPA 1985, London,

OSPAR, 1999. Guidelines on Artificial Reefs (Annex 6) In Relation to Living Marine Resources, 1999 Ospar Convention for the Protection of the Marine Environment of the North-East Atlantic; 21-24 June 1999 Meeting of the Ospar Commission, Kingston Upon Hull,

Pickering H., 2000. Legal Framework Governing Artificial Reefs in the European Union. In: Jensen, A., Collins, K., and Lockwood, A.P.M (ed), Artificial Reefs in European Seas, Dortrecht, The Netherlands, Kluwer Academic Press.

Pilarczyk K. W., 1998. Composite breakwaters utilizing geosystems. Coastlines, Structures and Breakwaters ed., Institute of Civil Engineers. N.W.H. Allsop. Thomas Telford, pp. 278293.

Ranasinghe R., Turner I. L. and Symonds G., 2006. Shoreline response to multi-functional artificial surfing reefs: A numerical and physical modelling study. Coastal Engineering, 53, 589-611.

Raybould M. and Mules T., 1998. Northern Gold Coast Beach Protection Strategy: A BenefitCost Analysis, Report prepared for Gold Coast City Council,

Simioni B. and Esteves L. S., 2010. Analysing the performance of multi-functional artificial reefs. Revista de Gestão Costeira Integrada, 10, 127-145 (full text in Portuguese, extended abstract in English).

Turner I. L., Aarninkhof S. G. J., Dronkers T. D. T. and McGrath J., 2004. CZM application of Argus coastal imaging at the Gold Coast, Australia. Journal of Coastal Research, 20, 739752.

Whitmarsh D., 1997. Editorial; Artificial Reefs: the Law and the Profits. Marine Pollution Bulletin, 34, 2-3.

Whitmarsh D. and Pickering H., 2000. Investing in Artificial Reefs. In: Jensen, A. C., Colins, K.J. and Lockwood, A.P.M. (ed), Artificial Reefs in European Seas, Dortrecht, The Netherlands, Kluwer Academic Publishers. 